\title{
A content and quality evaluation of ACGME-accredited reproductive endocrinology and infertility fellowship program webpages
}

\author{
Alexandra Peyser ${ }^{1,2}$ (I) $\cdot$ Baruch Abittan ${ }^{1,2} \cdot$ Christine Mullin $^{1,2} \cdot$ Randi H. Goldman ${ }^{1,2}$ \\ Received: 15 December 2020 / Accepted: 11 January 2021 / Published online: 18 January 2021 \\ (C) This is a U.S. government work and not under copyright protection in the U.S.; foreign copyright protection may apply 2021
}

\begin{abstract}
Purpose To analyze the content of websites of ACGME-accredited REI fellowship programs in the USA and to determine whether there are differences in content across geographic regions.

Methods All ACGME-accredited REI fellowship websites active as of September 2020 were evaluated and reviewed using 20 criteria in the following nine domains: program overview, contact information, application information, curriculum, current fellows, research, alumni, faculty, and fellowship benefits. Website content was compared across geographic regions (Northeast, Midwest, South, and West) of the USA. Analyses were completed using chi-squared univariate tests with $p<0.05$ considered statistically significant.

Results Out of the 49 accredited REI fellowship programs, 45 (92\%) had a dedicated website. The most commonly available information included a program description (88\%), clinical sites (84\%), and application requirements (78\%). Programs less commonly shared information regarding research requirements and didactics (65\% for each). Current fellows were featured in $55 \%$ of websites with their pictures displayed in $41 \%$ and ongoing research in $20 \%$. Salary and alumni information were included in only $14 \%$ and $12 \%$ of sites, respectively. When comparing content by geographic region, programs in the South had less information regarding application requirements $(\mathrm{p}<0.001)$, interview dates $(\mathrm{p}=0.03)$, and clinical sites $(\mathrm{p}=0.04)$ compared to all other regions.

Conclusions REI fellowship websites have significant variability in content available to applicants, and many are lacking information about core fellowship requirements. An informative and well-constructed website has the potential to improve perception of a graduate program.
\end{abstract}

Keywords Reproductive endocrinology $\cdot$ Infertility $\cdot$ Fellowship $\cdot$ Webpages $\cdot$ Websites

\section{Introduction}

Prospective reproductive endocrinology and infertility (REI) fellows often rely on the Internet to obtain valuable information regarding the unique qualities of different fellowship programs. Websites not only act as an important source of content

Alexandra Peyser

peysera@gmail.com

1 Division of Reproductive Endocrinology, Department of Obstetrics and Gynecology, Northwell Health, North Shore University Hospital, 300 Community Drive, Manhasset, NY 11030, USA

2 Donald and Barbara Zucker School of Medicine at Hofstra/ Northwell, Hempstead, NY, USA but also contribute to an applicant's first impression of a fellowship program [1].

Multiple studies have analyzed the comprehensiveness of training programs' websites across a variety of residencies and fellowships [2-7]. In fact, applicants aspiring to enter a specialty or subspecialty have reported that their decisions to apply to, interview at, and rank individual programs are heavily influenced by the quality and content of the program's website $[1,8,9]$. It has been shown that obstetric and gynecology $(\mathrm{Ob} / \mathrm{Gyn})$ residents invest a substantial portion of their time determining residency programs of interest using the Internet, which was determined to be one of the most effective means for applicants to learn about programs [6]. It can be expected that $\mathrm{Ob} / \mathrm{Gyn}$ residents will also use the Internet to explore their fellowship options as well.

To our knowledge, no published study has analyzed the availability and content of REI training program websites. 
Given the most recent COVID-19 pandemic in 2020, all REI fellowship programs held interviews virtually, likely making websites a first stop for applicants to learn about programs they would apply to. It is possible that in the future, virtual interviews will become a mainstay of the fellowship application process. Therefore, we sought to assess the current state of all ACGME-accredited REI fellowship program websites. The purpose of this study was to evaluate the presence and content of all REI training program websites and to determine whether there were differences in available electronic content across geographic regions.

\section{Materials and methods}

A list of all ACGME-accredited REI fellowship websites active as of September 2020 was obtained from the ACGME website (www.acgme.org). Website(s) for each program were searched for and accessed by an individual reviewer (AP) in September 2020 over the course of 1 week. In order to evaluate the accessibility of fellowship websites, the most common search engine was used (www.google.com). The search phrase used included "program name + REI fellowship." In addition, it was determined whether fellowships had a functioning link on the ERAS (Electronic Residency Application Service) website, the uniform application system which applicants use to apply.

All websites were independently examined using twenty criteria in nine domains created by an REI associate fellowship program director and fellow (Table 1). The nine domains and criteria included program overview (program description), contact information (program director name, program address, phone number, coordinators email), application information (requirements, application deadline, interview dates), curriculum, (rotation schedule, clinical sites, research requirements, didactic schedule), current fellows (names, picture, research), alumni (names, jobs), faculty (names, research), and fellowship benefits (salary). Website content was compared across geographic regions (Northeast, Midwest, South, and West) of the USA as determined by the US Census (www.census.gov). A chi-squared univariate analysis was used with $p<0.05$ considered statistically significant. This study was reviewed and found to be exempt by the Northwell Health Institutional Review Board.

\section{Results}

Out of the 49 accredited REI fellowship programs in the USA, $45(92 \%)$ had a dedicated fellowship website. All 45 websites were available via Google Search and were displayed on the first page of search results. Twenty-nine programs (59\%) had
Table 1 Criteria evaluated on REI fellowship websites

\begin{tabular}{ll}
\hline Evaluation domain & Evaluation criteria \\
\hline Program overview & Program description \\
& Program director name \\
& Address/phone number/email \\
Application information & Application requirements \\
& Application deadline \\
Curriculum & Interview dates \\
& Rotation schedule \\
& Clinical sites \\
Current fellows & Research requirements \\
& Didactics \\
& Current fellow names \\
Alumni & Current fellow pictures \\
Faculty & Fellow research \\
Fellowship benefits & Alumni names \\
\end{tabular}

working hyperlinks on the ERAS site that prospective fellows could access.

No program offered a website that contained all 20 criteria. Two programs shared content regarding 19 criteria, with only salary information missing. The information most commonly available included a program description (88\%), clinical sites (84\%), application requirements (77\%), and application deadline $(69 \%)$. The application deadline for all programs was standardized in 2020 by the Society for Reproductive Endocrinology and Infertility (SREI) to a deadline of May 1; however, of the $69 \%$ of programs with deadline dates available, not all reported the May 1 deadline but rather an inaccurate date. Approximately two-thirds shared information regarding research requirements and didactics (65\% for each). More than half (53\%) of the programs did not disclose their interview dates on their websites. Current fellows were featured in 55\% of websites, with their pictures shown in $41 \%$ and ongoing research in $20 \%$. Salary and alumni information were included in only $14 \%$ and $12 \%$ of sites, respectively (Fig. 1).

Twenty accredited fellowship programs were located in the Northeast, 11 in the South, and 9 for both the Midwest and West. When comparing content by geographic region, programs in the South contained less information regarding application requirements $(4 / 11, p<0.01)$, interview dates $(2 / 11$, $p=0.03)$, and clinical sites $(7 / 11, p=0.04)$ compared to all other regions. There was no difference among all other criteria evaluated (Table 2). 
Fig. 1 Overall summary of the data available on REI fellowship websites

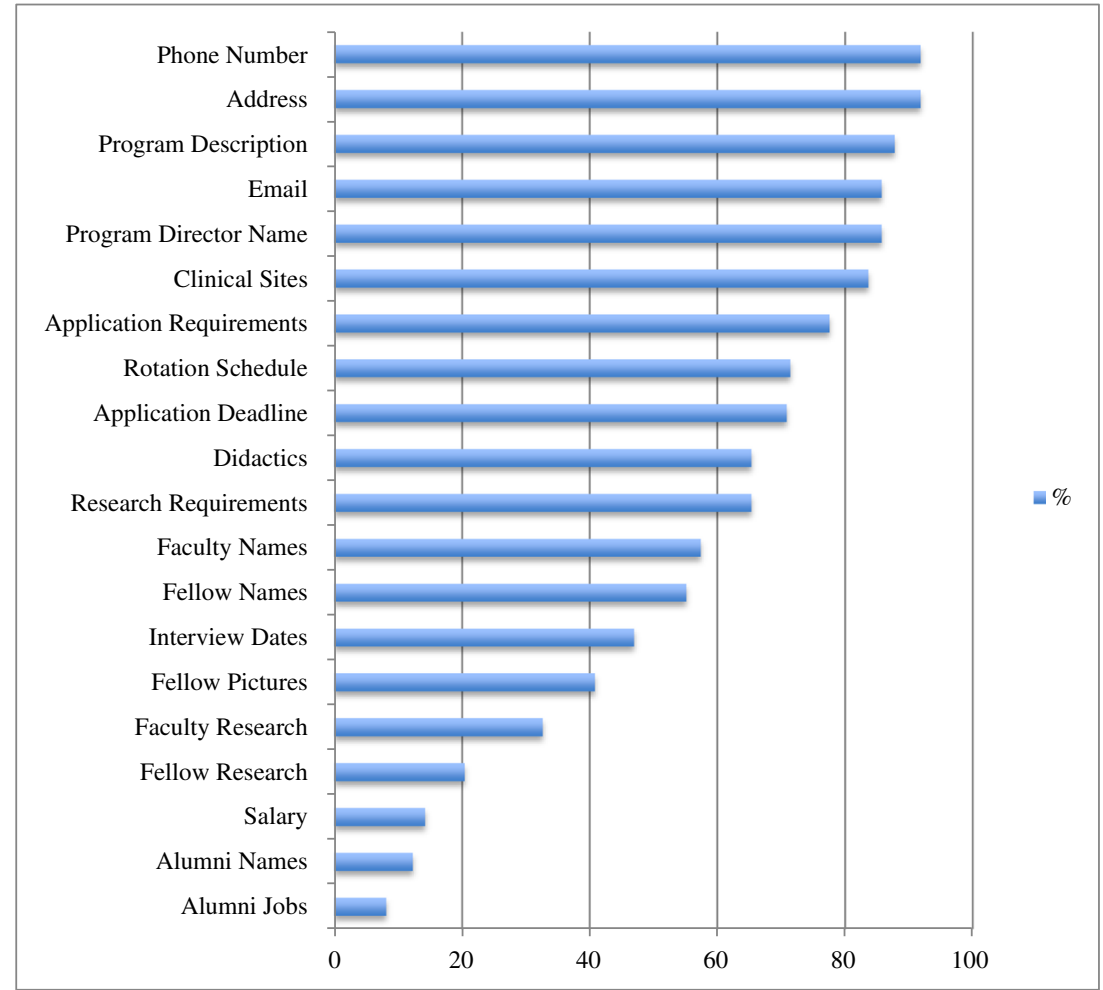

\section{Discussion}

Our study demonstrates that there is large variation in the amount of information available on REI fellowship websites. It is imperative for programs to design a comprehensive website; however, we found four programs which had no website at all. This study highlights deficiencies in the content and accessibility of existing websites, which is consistent with findings across other medical specialties. Previous studies analyzing the accessibility and content of websites in other fellowship programs, such as sports medicine, spine, shoulder, elbow, hand, and pediatric orthopedics, have consistently demonstrated these deficiencies with the goal of uncovering inadequacies and improving the match process for prospective trainees [10-12].

The results of this study suggest that many REI websites fail to provide essential information for prospective applicants. For busy $\mathrm{Ob} / \mathrm{Gyn}$ residents considering a career as a reproductive endocrinologist, word of mouth, on-site visits, away rotations, and websites are means by which one can learn about the unique offerings of different programs. Many obstacles preclude potential applicants from visiting a program, such as finances, geographic location, time, and this year in particular, the ongoing COVID-19 pandemic. The Internet serves as the most convenient and accessible means for applicants to learn about various programs. While it is unknown how a fellowship website may influence an applicant's final ranking, it remains a valuable tool in making a more cost-effective and selective interview process for both institutions and applicants.

The criteria we used was developed from prior studies to objectively analyze website content and provide programs with a useful template for website design $[8,13,14]$. Details on program overviews and curriculum were featured on a
Table 2 Website data by geographic region

\begin{tabular}{llllll}
\hline Region & Total $(n)$ & Website $(n)$ & $\begin{array}{l}\text { Application } \\
\text { requirements* }(n)\end{array}$ & Interview dates* $(n)$ & Clinical sites* $(n)$ \\
\hline Northeast & 20 & 18 & 17 & 8 & 18 \\
Midwest & 9 & 8 & 8 & 7 & 7 \\
South & 11 & 10 & $\mathbf{4}$ & $\mathbf{2}$ & $\mathbf{7}$ \\
West & 9 & 9 & 9 & 6 & 9 \\
\hline
\end{tabular}

*Criteria with significant differences between regions

Boldface indicates significant difference at $p<0.05$ 
majority of sites. Areas of content that lack particular attention across the websites we reviewed included fellow and faculty research, alumni jobs, and benefit information. A study by Charalel et al. reported the top 5 most valued website content preferences from a survey of interventional radiology fellowship applicants and found didactic information, facility information, rotation schedule, and research opportunities to be most valued by applicants. These criteria were only found in $65 \%, 84 \%, 71 \%$, and $65 \%$ of our study, respectively, highlighting the lack of important content as perceived by applicants on a majority of websites, and represent an avenue for improvement [15].

The REI fellowship match is administered by ERAS, which contains links to each program's dedicated website on their site. Despite these links, which should enable easy access for applicants, only 29 programs had functioning webpages linked by ERAS. REI fellowships began utilizing the ERAS system in 2019 to streamline the application process. In 2020, REI fellowships began implementing common deadlines across all programs to include synchronization of the application deadline, the date for notification regarding interviews, and the deadline for alerting candidates of their status (interview or waitlist). This process was similarly implemented by the maternal fetal medicine and gynecology oncology fellowship programs. Improvements in accessibility and quality of training program websites will further enhance the application process for prospective trainees to obtain useful information for the match process.

Previous studies have evaluated the presence or absence of contact information such as address, phone numbers, and program director email addresses on program websites [16]. While many applicants seek this information, programs may be wary to post this information in a public forum. We suggest that programs create a dedicated email address specifically for their fellowship or to have a program coordinators' contact information be easily accessible to applicants. In order to improve the inclusivity of all programs, we propose the following changes: first, to ensure that all programs have a working link on the ERAS website. Second, we suggest a centralized database, perhaps on the SREI website, which can list all active fellowship programs with common information that should be available from all programs to applicants. This would provide each applicant a standardized list of criteria from which to compare each program.

This study has several limitations. As data was collected over a 1-week time frame, we must consider that some websites may have been updated at a later date. The website variables assessed were chosen based on prior studies and may not comprehensively display the offerings of each unique program. It is possible that some health institutions have restrictions regarding public websites and limit information that is available. In addition, this study determined the presence of information but did not evaluate for the substance of the information shared. For example, some programs were more descriptive than others regarding their clinical schedule. Some programs discussed expectations for each fellowship year, while others listed specific topics expected to be mastered by the end of each year.

\section{Conclusions}

REI fellowship websites have significant variability in content available to applicants, and many lack information about core fellowship requirements. An informative and well-constructed website has the potential to improve perception of a graduate program. In addition, improving website content may have implications in the recruitment of competitive applicants, limiting financial and time constraints, and increases satisfaction with match results. More standardized program information can provide greater opportunity for applicants to compare and contrast unique programs. Further studies are needed to ascertain the specific interests of REI applicants and their satisfaction with the content quality of currently available webpages.

Code availability Not applicable.

Authors' contributions AP and RG designed the study. AP collected and reviewed the data. AP and RG analyzed the data. AP, BA, CM, and RG were major contributors in writing the manuscript. All authors read and approved the manuscript.

Data availability The datasets used analyzed during the current study are available from the corresponding author on reasonable request.

\section{Compliance with ethical standards}

Competing interests The authors declare that they have no competing interests.

Abbreviations REI, Reproductive endocrinology and infertility; SREI, Society for Reproductive Endocrinology and Infertility; ERAS, Electronic Residency Application Service

\section{References}

1. Embi PJ, Desai S, Cooney TG. Use and utility of web-based residency program information: a survey of residency applicants. J Med Internet Res. 2003;5:e22.

2. Svider PF, Gupta A, Johnson AP, Zuliani G, Shkoukani MA, Eloy JA, et al. Evaluation of otolaryngology residency program websites. JAMA Otolaryngol Head Neck Surg. 2014;140:956-60.

3. Skovrlj B, Silvestre J, Ibeh C, Abbatematteo JM, Mocco J. Neurosurgery residency websites: a critical evaluation. World Neurosurg. 2015;84:727-33.

4. Oladeji LO, Yu JC, Oladeji AK, Ponce BA. How useful are orthopedic surgery residency web pages? J Surg Educ. 2015;72:1185-9. 
5. Ashack KA, Burton KA, Soh JM, Lanoue J, Boyd AH, Milford EE, et al. Evaluating dermatology residency program websites. Dermatol Online J. 2016;22

6. Foster AM, Jackson CB, Martin SB. Reproductive health and cyber (mis) representations: a content analysis of obstetrics and gynecology residency program websites. Contraception. 2008;78:99-105.

7. Plas TLV, Novin SA, Yi PH. How comprehensive are nuclear medicine residency websites? World J Nucl Med. 2018;17:223-7.

8. Gaeta T, Birkhahn L, Lamont D, Banga N, Bove J. Aspects of residency programs' web sites important to student applicants. Acad Emerg Med. 2005;12:89-92.

9. Reilly E, Leibrandt T, Zonno A, Simpson M, Morris J. General surgery residency program websites: usefulness and usability for resident applicants. Curr Surg. 2004;61:236-40.

10. Silvestre J, Guzman JZ, Skovrlj B, Overley SC, Cho SK, Qureshi $\mathrm{SA}$, et al. The internet as a communication tool for orthopedic spine fellowships in the United States. The Spine Journal. 2015;15(4): 655-61.

11. Trehan SK, Morrell NT, Akelman E. Accredited hand surgery fellowship web sites: analysis of content and accessibility. The Journal of Hand Surgery. 2015;40(4):778-82.
12. Young BL, Oladeji LO, Cichos K, Ponce B. Content and accessibility of shoulder and elbow fellowship web sites in the United States. The Iowa Orthopaedic Journal. 2016;36:36-40.

13. Hansberry D, Bornstein J, Agarwal N, et al. An assesment of radiology residency program websites. J Am Coll Radiol. 2018;15: 663-6.

14. Deloney L, Perrot L, Lensing S. Radiology resident recruitment: a study of the impact of web-based informatin and interview day activites. Acad Radiol. 2014;21:931-7.

15. Charalel R, Pua B, Galla N, et al. Intervential radiology fellowship website content: what is the relevance to potential applicants'? Clin Imaging. 2016;40:1070-4.

16. Huntington WP, Haines N, Patt JC. What factors influence applicants' rankings of orthopaedic surgery residency programs in the National Resident Matching Program? Clin Orthop Relat Res. 2014;472:2859-66.

Publisher's note Springer Nature remains neutral with regard to jurisdictional claims in published maps and institutional affiliations. 